\title{
Surgical Management of Vascular anomalies
}

\author{
Roshni Dasgupta
}

Published online: 18 September 2014

(C) Springer Science+Business Media New York 2014

\begin{abstract}
Vascular anomalies have been historically divided into tumors and malformations based on the Mulliken and Glowacki classification system. Vascular malformations are also further subdivided into simple and combined based on vessel types. Surgical treatment has historically been the mainstay of treatment. With the advent of multi-disciplinary vascular anomaly clinics, the use of novel medical treatments, and the increased use of sclerotherapy, the role of surgery has been refined. Surgery is often now used in combination with other therapies and remains an integral tool for the management of the patient with vascular anomalies.
\end{abstract}

\section{Keywords Hemangioma - Kaposiform} hemangioendothelioma · Lymphatic malformation · Venous malformation - Arteriovenous malformations

\section{Introduction}

Mulliken and Glowacki, in 1982 created a classification system of vascular anomalies [1]. This classification was later adopted in 1996 by the International Society for the Study of Vascular Anomalies (ISSVA) at the 1996 meeting in Rome [2]. This schema divided vascular anomalies into tumors and malformations and provided the framework for great strides in research and treatment. The classification system was recently expanded at the 2014 ISSVA workshop in Melbourne. This revision was essential to fully

\footnotetext{
R. Dasgupta $(\bowtie)$

Division of Pediatric General and Thoracic Surgery, Cincinnati Childrens Medical Center, 3333 Burnet Ave, ML2023, Cincinnati, OH 45229, USA

e-mail: roshni.dasgupta@cchmc.org
}

encompass the advances in knowledge in the past decade and a half. This new system again divides vascular anomalies into tumors and malformations but now provides greater detail including newly named anomalies, clinical associations, and identified genes, further details can be found at www.issva.org.

Vascular tumors are now divided into benign, locally aggressive, and malignant entities. Hemangiomas are subclassified by pattern and location to encompass syndromic associations such as PHACES and LUMBAR, which now allow clinicians to ensure they treat all aspects of the syndrome involved [3, 4]. Vascular malformations are also further subdivided into simple and combined based on vessel types that are involved. There has historically been diagnostic difficulty in the treatment of vascular anomalies, and these new classifications allow for ease of communication between specialists as well as greater understanding of treatment options including medical, interventional, and surgical options [5].

Surgical treatment has long been a mainstay of management for vascular anomalies, over the years; however, its role has been refined, and in many cases is now used in combination with other interventions to provide for the best possible outcome for the patient and improve quality of life.

\section{Hemangioma}

Hemangiomas of infancy generally follow a predetermined course of proliferation and involution, but exhibit wide variation in the rate, duration, and degree of growth and spontaneous tumor regression. The proliferative phase begins in the first few weeks after birth and typically continues for 6-9 months. During this proliferation, there 
is increased endothelial cell hyperplasia. Following this phase, the growth rate of lesions generally stabilizes and grows with the child. The slow involution phase then begins. Most hemangiomas undergo some degree of involution. Complete involution of the lesion occurs in $50 \%$ of patients by age 5 and in $70 \%$ by age 7 [6॰]. Other lesions may continue to regress until ages 9 to 10 . However, only about half of patients have normal skin after the hemangioma has completely regressed. In the remainder of patients, however, the skin can, however, exhibit various degrees of skin atrophy, a fibro fatty residuum, wrinkling, telangiectasias, yellowish inelastic patches, or scars where previous ulceration occurred during proliferation, which often require surgical correction. Congenital hemangiomas are distinct from infantile hemangiomas and are classified into rapidly involuting and non-involuting subtypes [7]. The non-involuting congenital hemangioma (NICH) often requires surgical management $[8,9]$.

There are certain regions particularly within the head and neck, which have specific concerns and indications for early surgical or medical management. Peri-orbital lesions can cause proptosis with corneal exposure, strabismus and amblyopia, optic atrophy, and bony malformation, and require periodic ophthalmologic evaluation throughout the life cycle of the hemangioma. If lesions occlude the visual fields, long-term development of visual pathways may be compromised and is among the most urgent hemangiomas to be treated. Nasal tip Hemangiomas can often cause longterm destruction of the cartilage, and early treatment and often surgical management is indicated to prevent irreversible damage. Parotid hemangiomas are often quite large before they come to presentation and can be difficult to treat. Hemangiomas of the lip can also be troublesome as they often interfere with feeding and are more prone to ulceration [10].

There are also certain patterns of hemangiomas particularly in the head and neck, which are important to recognize and screen for known associations which may require further surgical management. PHACE Syndrome involves a segmental type hemangioma with associated structural abnormalities of the brain, aorta, eyes, cerebral vasculature, aorta, and chest wall. A recent consensus statement was published creating major and minor diagnostic criteria [3]. Patients with large facial hemangiomas $5 \mathrm{~cm}$ or greater appear to have increased risk of PHACES syndrome and should be screened for associated anomalies. Screening includes an MRI of the brain, echocardiogram, ophthalmic examination, and MRA of the chest (Fig. 1).

Airway Hemangiomas must be looked for in patients who present with hemangiomas in the cervicofacial region that covers a bearded distribution (i.e., the pre-auricular regions, chin, lower lip, and neck) may be associated with subglottic hemangiomas. These hemangiomas may cause significant airway compromise in the proliferative period of growth. These patients should undergo a screening endoscopy to determine if there is airway involvement. Airway hemangiomas may also occur in the absence of skin involvement or in association with lesions of the chest. In such cases, endoscopic evaluation of the airway is advised prior to the implementation of a treatment strategy. Many of these patients require tracheostomy to help prevent airway compromise during the proliferative period despite the concomitant use of medical therapies.

Many hemangiomas do not require medical or surgical management and will involute with simply supportive measures. Propranolol has become first-line therapy for treatment of hemangiomas and has changed the need for surgical management of hemangiomas [11]. Propranolol is very efficacious in preventing the rapid proliferation and therefore, prevents much of the disfiguring proliferation noted with alternative therapies such as steroids. However, there continues to be a subset of patients whom despite the use of propranolol who will benefit from surgical resection. These include patients who fail medical management or have localized disease can be treated easily with excision. Surgical resection is often curative for cutaneous hemangiomas and may be indicated in a number of clinical circumstances. In the proliferative period, when hemangiomas present with a threat to function or are associated with complications such as ulceration, bleeding, and infection or do not respond to pharmacotherapy or other less-invasive alternatives. Hemangiomas that are pedunculated have a high probability of leaving significant fibrofatty residuum. Hemangiomas that persist beyond a reasonable period of time or grow atypically can also be removed. When there is a perceived emotional burden on the child or family and the lesion can easily be removed, leaving no significant cosmetic deformity, resection should also be considered.

The actual timing of surgery is controversial, particularly as the ultimate results of spontaneous involution are very difficult to predict particularly now with the use of propranolol. If surgical excision is required in order to avoid the psychosocial consequences of a visible hemangioma, the operation should be performed during the preschool period, prior to the child is beginning to develop a defined body image.

The surgical approach depends on the size and location of the hemangioma. Although lenticular excision is a wellestablished approach for localized lesions, the length of scarring can sometimes be a disadvantage. Circular excision with purse-string closure has also been described for removal of infantile hemangiomas, with excellent results $[12,13]$. The nasal tip hemangioma historically has always required surgical resection to prevent long-term deformities. Nasal tip hemangiomas often require surgical resection; however, with the advent of propranolol, there may be 

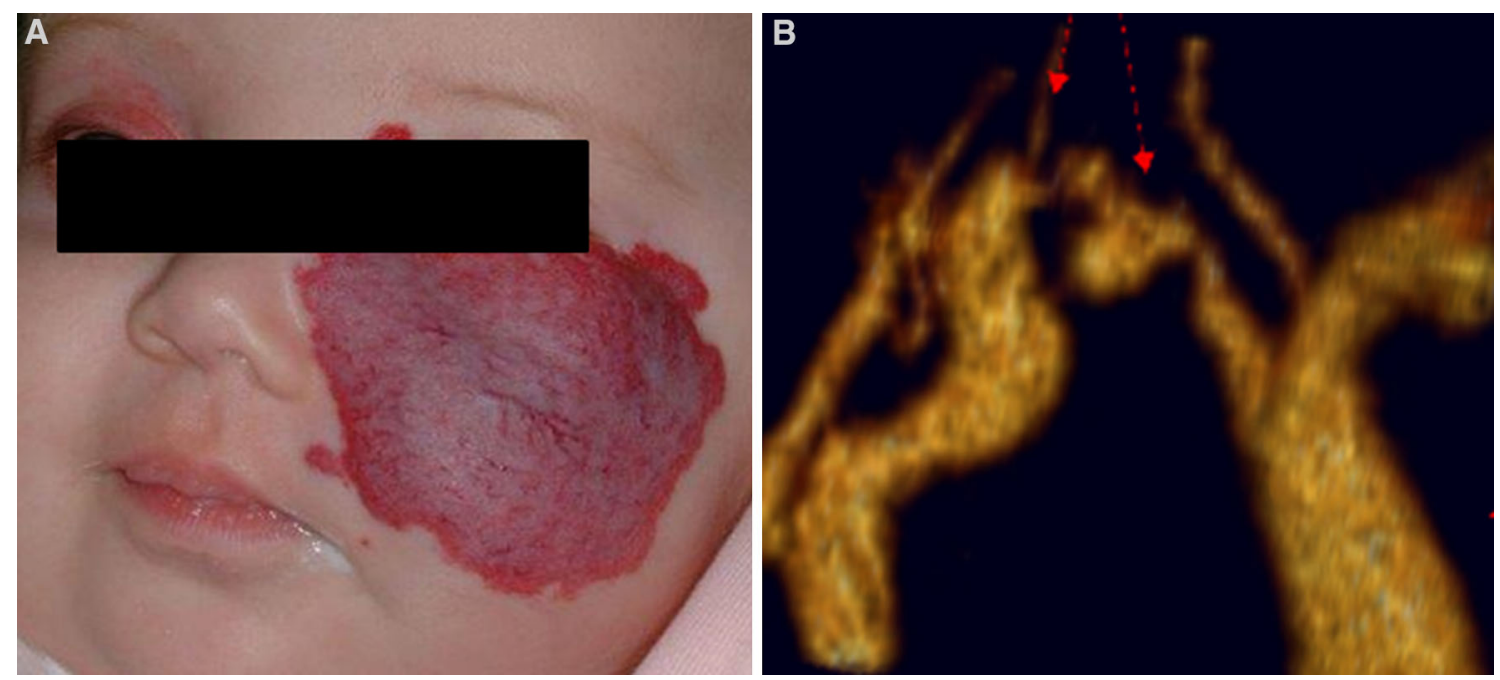

Fig. 1 a Segmental hemangioma $\mathbf{b}$ aortic coarctation associated with PHACES that required urgent surgical correction

a decreased need for resections [14] thought to be due to decrease the fatty residual bulk that can damage the cartilage. Many techniques are described for correction of nasal tip deformities [15]. These including the standard external rhinoplasty, an elliptical midline incision, and a modified subunit incision described by Waner in 2008 [16]. Parotid hemangiomas can also pose challenges and a large number of patients requiring surgical reconstruction after involution [17].

Pulsed dye laser (PDL) has also been used for the treatment of cutaneous hemangioma; however, its use in proliferating is controversial. PDL does not prevent the growth of a deep subcutaneous component. The routine use of the PDL is not recommended; a randomized controlled study conducted noted that PDL treatment of uncomplicated hemangiomas had no clinical benefit as compared with observation without treatment [18]. However, PDL is important for the selected treatment of ulcerated hemangiomas that cannot be resected by decreasing pain and promoting more rapid re-epithelialization [19]. This approach is particularly helpful in anatomical areas that are not amenable to resection, such as extensive facial or perineal lesions. Furthermore, PDL can also be used to treating residual telangiectasia left after involution of the hemangioma.

\section{Kaposiform Hemangioendothelioma}

Kaposiform Hemangioendothelioma (KHE) is an aggressive vascular tumor, presenting at birth in about $50 \%$ of cases and usually appearing within the first year of life in most other cases. The tumor is usually solitary, and multifocal lesions are rare [20•]. Unlike hemangiomas, KHE has no female preponderance and usually occurs in the proximal arms and legs and the trunk including the retroperitoneum. KHE is typically manifested as a plaque-like mass with a deep red-purple hue. It is associated with surrounding subcutaneous edema and induration the degree of which depends on the amount of trapped blood elements and the extent of intralesional bleeding in tissue. KHE lesions can involve adjacent muscle and bone and is locally aggressive but does not metastasize. The mortality rate of this tumor is high, ranging from 20 to $37 \%$, with bleeding being the primary cause of death. Retroperitoneal involvement has been associated with a particularly poor outcome. These infiltrative lesions can invade skin, subcutaneous fat, and muscle planes. KHEs can cause a coagulopathy called Kasabach-Merritt Phenomenon (KMP), which carries a mortality rate of $20-30 \%$. This involves platelet trapping resulting in profound thrombocytopenia, an enlarging lesion, and a consumptive coagulopathy with significant hypofibrinogenemia.

While there have not been any prospective clinical trials regarding the treatment of KHE, a consensus statement on management has been published [20 ${ }^{\bullet}$. For medical therapy, both the use of sirolimus, steroids, vincristine, or propranolol have been utilized with small series showing positive results [21, 22]. If a lesion is completely resectable without significant morbidity, it should be surgically removed as this would be curative. Unfortunately, there are relatively few lesions that this is possible for. Arterial embolization has also been used for high-flow tumors including KHE in patients with high-output cardiac failure who have not responded to aggressive pharmacologic management [23]. If a lesion is resectable, embolization can also be performed prior to resection to minimize intraoperative blood loss. 


\section{Lymphatic Malformations}

Lymphatic malformations have a prevalence if 2.8 per 100,000 hospital admissions [24]. There are no known racial or sex predilection. Lymphatic malformations encompass a wide spectrum of abnormalities and are considered slow flow lesions. There are three primary types of lymphatic malformations: microcystic, macrocystic, and combined. Lymphatic malformations can be seen in any anatomical region but are more commonly seen in rich lymphatic areas; these include the head and neck, axilla, mediastinum, groin, and retroperitoneum.

\section{Cervical Malformations}

The prenatal diagnosis of cervical lymphatic malformations has significant implications. Large anterior cervical and lingual lesions may be associated with airway obstruction, and prenatal diagnosis should influence the mode, timing, and place of delivery. These patients often require the presence of a skilled surgical team capable of performing an ex utero intra-partum treatment or EXIT procedure where an airway is secured, while the infant is still under maternal placental support. Several studies have examined EXIT procedures with large vascular neck masses, and have found it to be essential for the management of these complex patients [25]. Initially endotracheal intubation is desired, however, as many of these lesions have airway involvement, over half of the patients require permanent tracheostomy tube placement [26]. The overall outcome for these patients is poor; those who do survive are often left with permanent nerve palsies and regrowth of the lesion $[25,27]$.

Large cervical lesions can also be associated with Turner or Noonan syndrome, as well as other congenital anomalies. They carry a high prenatal mortality rate, particularly with hydrops and diffuse lymphedema. Amniocentesis with genetic and family counseling should be provided for these patients. All patients with cervical cystic lesions should have a chest radiograph obtained to determine the presence or absence of mediastinal involvement. MRI is the modality of choice to determine the extent of the malformation and relationship to soft tissues, nerves, muscle, and vascular structures [28].

Management of these patients is complex and requires a multi-disciplinary team with expertise and long-term followup of these patients. Treatment of patients with lymphatic malformations depends on the clinical presentation, the size of the lesion, the anatomical location, and the presenting complications.

Patients with lymphatic malformations of the head and neck often have numerous functional issues. These include issues with dentition, dysphagia, dysarthria, infection, and bleeding of malformations. Enlargement can occur with infection and in turn may cause obstruction of the airways, requiring intubation or tracheostomy. Psychological sequelae can also arise as the child grows older and becomes increasingly aware of the lesion and present for surgical management.

A multi-disciplinary clinic environment experienced in the nuances of care of children with vascular anomalies should help determine a comprehensive treatment plan that may use both medical and interventional modalities alone or in combination. First-line medical management in our group has transitioned from interferon and other agents to sirolimus. Sirolimus, an m-Tor inhibitor has been shown to improve quality of life and decrease burden of disease in patients with extensive lymphatic malformations [29•].

\section{Interventional Management}

Sclerotherapy has generally become the first-line treatment for symptomatic macrocystic lymphatic malformations. A number of sclerosing agents have been used, including doxycycline, ethanol, bleomycin, OK-432, and fibrin glue. Doxycycline is most commonly used in our clinical practice; it is an anti-microbial which inhibits protein synthesis [30]. Bleomycin is another sclerosant agent, which has been had some reported success with microcystic malformations [31]. The use of sclerotherapy for lesions in the head and neck is particularly common but should be supported by a multi-disciplinary team. Post sclerotherapy swelling and airway compromise have been noted, and peri-operative intubation or tracheostomy may be required [32].

Surgical management plays an important role in the management of lymphatic malformations. It has been most useful in resection of microcystic disease not responsive to sclerotherapy, debulking, and resection of smaller lesions. Smaller and superficial malformations are generally amenable to complete excision with excellent results. Larger lesions that involve deep structures of the neck, tongue, and mediastinum entail the risk of multiple complications, including fistula formation, infection, damage to vascular structures, damage to nerves, and cosmetic deformity but are often required to improve functional outcomes.

Lymphatic malformations of the tongue can pose a significant functional problem for patients, as only partial resection is possible, and malformations are microcystic and generally not responsive to sclerotherapy [33]. Partial debulking of the tongue can be performed and residual tissue may be treated with bleomycin, laser, or other coblation treatments $[32,34]$. Results are mixed and recurrence of disease is the norm. There are some early positive 
results with the combination of sirolimus and surgical resection with favorable results.

In general, surgical debulking in patients with overgrowth secondary to lymphatic malformations is important to allow for increased function and improved mobility. This has also been anecdotally shown to decrease infections. This generally involves staged procedures and the uses techniques such as the judicious use of fibrin glue and long term closed suction drains, which are important in the management of the often prolonged lymphatic leakage that may occur post-surgical debulking. We have found the adjunct use of sirolimus has allowed more rapid removal of drains and decreased post-operative complications secondary to lymphatic leakage.

Laser treatment is often very helpful in treating the lymphatic blebs that are present on the skin overlying lymphatic malformations which represent dermal involvement with malformation. This is also often seen within resection scars. These blebs often leak lymphatic fluid and provide a portal of entry for bacteria. Laser ablation using $\mathrm{CO}_{2}$ or KTP laser helps prevent leakage and cellulitis. Lymphatic vesicles often recur, and re-treatment with laser is often necessary.

\section{Venous Malformations}

Congenital venous malformations (VM) are a common vascular malformation and are thought to be due to a localized developmental defect of the vasculature characterized by enlarged endothelial cell venous channels surrounding by sparsely distributed vascular smooth muscle $[35,36]$. VM's can be superficial or deep, limited to the dermis and subcutaneous tissues or deeper and can even infiltrate muscle or bone. They can be present throughout the body and grow in proportion to the child and do not involute. The most common symptom ascribed to VM's is pain. Venous malformations may also enlarge and become symptomatic with trauma, puberty, or during pregnancy. Without treatment over time, VM will generally undergo expansion. Coagulation abnormalities are also common with in patients with extensive VM's and must be considered when making plans for intervention.

\section{Interventional Treatment}

The treatment of the patient with venous malformations is individualized and best treated within a multi-disciplinary forum. The location of the malformation, extent of the lesion, and most importantly the symptoms of the patient are important to consider in the development of a comprehensive treatment plan with the primary goal-being alleviation of symptoms. When intervention is decided upon, generally sclerotherapy or surgery or a combination of the two is chosen. Low molecular weight heparin is commonly administered peri-procedurally for patients with elevated d-dimers. Our practice is to treat patients for 2 weeks prior and 2 weeks after the procedure.

Sclerotherapy is often considered first-line treatment [37-40]. Common sclerosants for venous malformations include dehydrated ethanol and detergent sclerosants such as sodium tetradecyl sulfate (STS), polidocanol, sodium morrhuate, and ethanolamine [37-40]. Surgery may also be performed with pre-operative sclerotherapy to help decrease risks of intraoperative bleeding in these larger lesions and to better define the malformation to be excised and is generally done within $48 \mathrm{~h}$ of sclerotherapy. When a lesion is localized, and does not involve vital structures, surgical excision alone can result in excellent outcomes with minimal risk of recurrence. More extensive lesions are generally not amenable to resection or are only partially resectable. Surgical resection of VM may also be useful, when sclerotherapy cannot be safely performed due to the location of the lesion or when a lesion is too large for effective sclerotherapy.

Glomuvenous malformations are best managed by complete surgical resection. These are bluish raised nodules which tend to involve the skin and subcutaneous tissues and are often painful on palpation. Symptomatic glomuvenous malformations are best managed by complete surgical excision if possible. Unfortunately, they are often widespread and not easily amenable to excision.

\section{ArterioVenous Malformations}

Arteriovenous malformations (AVMs) are congenital vascular lesions associated with a variable degree of arteriovenous shunting. These high-flow communications between arteries and veins are among the most dangerous vascular anomalies. The fast-flow character of AVMs usually becomes evident in childhood or during puberty. AVMs most commonly occur in the head and neck, but trunk and extremity involvement is also seen. MRA is the best modality to demonstrate extent, delineate the nidus or connections between the arterial and venous systems. Often, pain, expansion of the lesion, ulceration, bleeding, or cardiac decompensation occurs. If symptomatic, intervention is indicated. Intra-arterial embolization of the nidus combined with surgical excision currently offers the best chance for cure, but complete excision may be impossible because of location and extent of the malformation. Complex lesions require creative operations, tailored to individual pathology and anatomy. When lesions cannot be excised, palliative embolization may be appropriate to control symptoms. Embolization techniques include the use 
of metal coils, particles, and glues such as onyx [41]. Lesions often recur and close followup post intervention is important. Long-term complications include cardiac hypertrophy, cardiac failure, and cardiac instability, as well as hemorrhage and stroke.

\section{Conclusion}

Surgery for vascular anomalies is an important tool and should be performed as a part of a comprehensive treatment plan. The surgical goal should be the improvement of symptoms and quality of life rather than eradication of the lesion at the expense of surgical morbidity. These patients should be seen and followed long term in multi-disciplinary vascular anomaly clinics.

\section{Compliance with Ethics Guidelines}

Conflict of Interest Roshni Dasgupta declares that she has no conflict of interest.

Human and Animal Rights and Informed Consent. No human or animal studies performed by the authors: This article does not contain any studies with human or animal subjects performed by any of the authors.

\section{References}

Papers of particular interest, published recently, have been highlighted as:

- Of importance

1. Mulliken JB, Glowacki J. Hemangiomas and vascular malformations in infants and children: a classification based on endothelial characteristics. Plast Reconstr Surg. 1982;69:412-22.

2. Enjolras O, Deffrennes D, Borsik M, Diner P, Laurian C. Vascular "tumors" and the rules of their surgical management. Ann Chir Plast Esthet. 1998;43:455-89.

3. Metry D, Heyer G, Hess C, Garzon M, Haggstrom A, Frommelt P, Adams D, Siegel D, Hall K, Powell J, Frieden I, Drolet B, Conference PSR. Consensus Statement on Diagnostic Criteria for PHACE Syndrome. Pediatrics. 2009;124:1447-56.

4. Hartzell, L. D. \& Buckmiller, L. M. Current management of infantile hemangiomas and their common associated conditions. Otolaryngol Clin North Am. (2012);45, 545-56, vii.

5. Greene AK, Liu AS, Mulliken JB, Chalache K, Fishman SJ. Vascular anomalies in 5,621 patients: guidelines for referral. J Pediatr Surg. 2011;46:1784-9.

6. - Drolet BA, Frommelt PC, Chamlin SL, Haggstrom A, Bauman NM, Chiu YE, Chun RH, Garzon MC, Holland KE., Liberman L, MacLellan-Tobert S, Mancini AJ, Metry D, Puttgen KB, Seefeldt M, Sidbury R, Ward KM, Blei F, Baselga E, Cassidy L, Darrow DH, Joachim S, Kwon EK, Martin K, Perkins J, Siegel, DH, Boucek RJ Frieden IJ. Initiation and use of propranolol for infantile hemangioma: report of a consensus conference.
Pediatrics. 2013;131, 128-40. This is a seminal paper providing a consensus on how to initiate and treat patients with propranol.

7. Mulliken JB, Enjolras O. Congenital hemangiomas and infantile hemangioma: missing links. J Am Acad Dermatol. 2004;50: 875-82.

8. Lee PW, Frieden IJ, Streicher JL, McCalmont T, Haggstrom AN. Characteristics of noninvoluting congenital hemangioma: a retrospective review. J Am Acad Dermatol. 2014;70:899-903.

9. Berenguer B, Mulliken JB, Enjolras O, Boon LM, Wassef M, Josset P, Burrows PE, Perez-Atayde AR, Kozakewich HP. Rapidly involuting congenital hemangioma: clinical and histopathologic features. Pediatr Dev Pathol. 2003;6:495-510.

10. Hynes S, Narasimhan K, Courtemanche DJ, Arneja JS. Complicated infantile hemangioma of the lip: outcomes of early versus late resection. Plast Reconstr Surg. 2013;131:373e-9e.

11. Leaute-Labreze C, Dumas de la Roque E, Hubiche T, Boralevi F, Thambo JB, Taieb A. Propranolol for severe hemangiomas of infancy. N Engl J Med. 2008;358:2649-51.

12. Wu JK, Rohde $\mathrm{CH}$. Purse-string closure of hemangiomas: early results of a follow-up study. Ann Plast Surg. 2009;62:581-5.

13. Mulliken JB, Rogers GF, Marler JJ. Circular excision of hemangioma and purse-string closure: the smallest possible scar. Plast Reconstr Surg. 2002;109:1544-54 discussion 1555.

14. Perkins JA, Chen BS, Saltzman B, Manning SC, Parikh SR. Propranolol therapy for reducing the number of nasal infantile hemangioma invasive procedures. JAMA Otolaryngol Head Neck Surg. 2014;140:220-7.

15. Hochman M, Mascareno A. Management of nasal hemangiomas. Arch Facial Plast Surg. 2005;7:295-300.

16. Waner M, Kastenbaum J, Scherer K. Hemangiomas of the nose: surgical management using a modified subunit approach. Arch Facial Plast Surg. 2008;10:329-34.

17. Greene AK, Rogers GF, Mulliken JB. Management of parotid hemangioma in 100 children. Plast Reconstr Surg. 2004;113:53-60.

18. Kessels JP, Hamers ET, Ostertag JU. Superficial hemangioma: pulsed dye laser versus wait-and-see. Dermatol Surg. 2013;39: 414-21.

19. David LR, Malek MM, Argenta LC. Efficacy of pulse dye laser therapy for the treatment of ulcerated haemangiomas: a review of 78 patients. Br J Plast Surg. 2003;56:317-27.

20. - Drolet BA, Trenor CC 3rd, Brandao LR, Chiu YE, Chun RH, Dasgupta R, Garzon MC, Hammill AM, Johnson CM, Tlougan B, Blei F, David M, Elluru R, Frieden IJ, Friedlander SF, Iacobas I, Jensen JN, King DM, Lee MT, Nelson S, Patel M, Pope E, Powell J, Seefeldt M, Siegel DH, Kelly M, Adams DM. Consensusderived practice standards plan for complicated Kaposiform hemangioendothelioma. J Pediatr. 2013;163, 285-91. This was again a consensus statement to develop medical and surgical treatment for Kaposiform Hemangioendothelioma.

21. Chiu YE, Drolet BA, Blei F, Carcao M, Fangusaro J, Kelly ME, Krol A, Lofgren S, Mancini AJ, Metry DW, Recht M, Silverman RA, Tom WL, Pope E. Variable response to propranolol treatment of kaposiform hemangioendothelioma, tufted angioma, and Kasabach-Merritt phenomenon. Pediatr Blood Cancer. 2012;59: 934-8.

22. Blatt J, Stavas J, Moats-Staats B, Woosley J, Morrell DS. Treatment of childhood kaposiform hemangioendothelioma with sirolimus. Pediatr Blood Cancer. 2010;55:1396-8.

23. Garcia-Monaco R, Giachetti A, Peralta O, Napoli N, Lobos P, Gioseffi L, Mariani G. Kaposiform hemangioendothelioma with Kasabach-Merritt phenomenon: successful treatment with embolization and vincristine in two newborns. J Vasc Interv Radiol. 2012;23:417-22.

24. Brouillard P, Boon L, Vikkula M. Genetics of lymphatic anomalies. J Clin Invest. 2014;124:898-904. 
25. Marwan A, Crombleholme TM. The EXIT procedure: principles, pitfalls, and progress. Semin Pediatr Surg. 2006;15:107-15.

26. Olutoye OO, Olutoye OA. EXIT procedure for fetal neck masses. Curr Opin Pediatr. 2012;24:386-93.

27. Emery PJ, Bailey CM, Evans JN. Cystic hygroma of the head and neck. A review of 37 cases. J Laryngol Otol. 1984;98:613-9.

28. Kathary N, Bulas DI, Newman KD, Schonberg RL. MRI imaging of fetal neck masses with airway compromise: utility in delivery planning. Pediatr Radiol. 2001;31:727-31.

29. • Hammill AM, Wentzel M, Gupta A, Nelson S, Lucky A, Elluru R, Dasgupta R, Azizkhan RG, Adams DM. Sirolimus for the treatment of complicated vascular anomalies in children. Pediatr Blood Cancer. 2011;57, 1018-24. This is the first paper that discusses sirolimus as a treatment for complex vascular anomalies, and provided a basis for a clinical trial that has just recently been completed. This is the first medical therapy that has improved quality of life of these complex patients.

30. Renton JP, Smith RJ. Current treatment paradigms in the management of lymphatic malformations. Laryngoscope. 2011;121:56-9.

31. Chaudry G, Guevara CJ, Rialon KL, Kerr C, Mulliken JB, Greene AK, Fishman SJ, Boyer D, Alomari AI. Safety and Efficacy of Bleomycin Sclerotherapy for Microcystic Lymphatic Malformation. Cardiovasc Intervent Radiol. 2014.

32. Boardman SJ, Cochrane LA, Roebuck D, Elliott MJ, Hartley BE. Multimodality treatment of pediatric lymphatic malformations of the head and neck using surgery and sclerotherapy. Arch Otolaryngol Head Neck Surg. 2010;136:270-6.
33. Azizkhan RG, Rutter MJ, Cotton RT, Lim LH, Cohen AP, Mason JL. Lymphatic malformations of the tongue base. J Pediatr Surg. 2006;41:1279-84.

34. Roy S, Reyes S, Smith LP. Bipolar radiofrequency plasma ablation (Coblation) of lymphatic malformations of the tongue. Int J Pediatr Otorhinolaryngol. 2009;73:289-93.

35. Limaye N, Wouters V, Uebelhoer M, Tuominen M, Wirkkala R, Mulliken JB, Eklund L, Boon LM, Vikkula M. Somatic mutations in angiopoietin receptor gene TEK cause solitary and multiple sporadic venous malformations. Nat Genet. 2009;41:118-24.

36. Brouillard P, Vikkula M. Genetic causes of vascular malformations. Hum Mol Genet. 2007;16 Spec No. 2, R140-9.

37. Behr GG, Johnson CM. Vascular anomalies: hemangiomas and beyond-part 2, Slow-flow lesions. AJR Am J Roentgenol. 2013;200:423-36.

38. Legiehn GM, Heran MK. A Step-by-Step Practical Approach to Imaging Diagnosis and Interventional Radiologic Therapy in Vascular Malformations. Semin Intervent Radiol. 2010;27:209-31.

39. Dubois J, Alison M. Vascular anomalies: what a radiologist needs to know. Pediatr Radiol. 2010;40:895-905.

40. Burrows PE, Mason KP. Percutaneous treatment of low flow vascular malformations. J Vasc Interv Radiol. 2004;15:431-45.

41. Thiex R, Williams A, Smith E, Scott RM, Orbach DB. The use of Onyx for embolization of central nervous system arteriovenous lesions in pediatric patients. AJNR Am J Neuroradiol. 2010;31: $112-20$. 